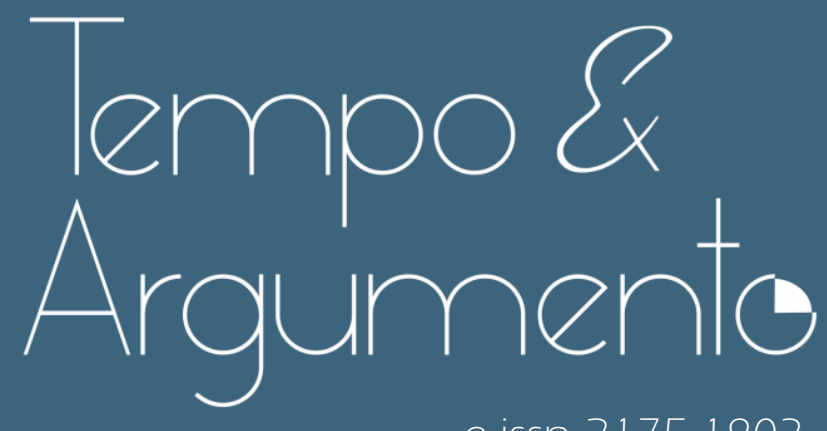

e-issn 2175-1803

\title{
Uma virada epistêmica feminista (negra): conceitos e debates
}

- Ana Maria Veiga

Doutora em História pela Universidade Federal de Santa Catarina (UFSC). Professora do Programa de Pós-Graduação em História e líder do grupo de pesquisa ProjetAH - História das Mulheres, Gênero, Imagens, Sertões da Universidade Federal da Paraíba (UFPB).

João Pessoa, PB - BRASIL

lattes.cnpq.br/5507849878186996

amveiga@yahoo.com.br

(iD) orcid.org/0000-0003-0446-1472

Para citar este artigo:

VEIGA, Ana Maria. Uma virada epistêmica feminista (negra): conceitos e debates. Tempo e Argumento, Florianópolis, v. 12, n. 29, e0 101 , jan./abr. 2020

do) http://dx.doi.org/10.5965/21751803122292020e0101

Recebido: 31/08/2019

Aprovado: 17/03/2020 


\title{
Uma virada epistêmica feminista (negra): conceitos e debates
}

\begin{abstract}
Resumo
Busco sistematizar neste artigo alguns debates que percebo como centrais para os feminismos negros americanos, tomando como sujeitos/as de análise mulheres intelectuais estadunidenses e brasileiras, tratando de suas singularidades e da complementaridade de falas e discursos repletos de afetos e de exemplos de vida. Considerando a virada epistêmica feminista das últimas décadas, a partir dos conceitos de interseccionalidade e (de)colonialidade, traço paralelos com base na localização de mulheres intelectuais negras, mapeando protagonismos de sujeitos/as em situação de margem, que trazem suas vivências para teorizações acadêmicas e enfrentamentos políticos, inspiradas seja pela voz de Sojourner Truth, nos EUA, ou pela "escrevivência" de Conceição Evaristo, no Brasil, junto com a confiança nos orixás e o respeito à ancestralidade de matriz africana. Falas localizadas e em primeira pessoa emergem dessas narrativas e confrontam epistemologias hegemônicas, trazendo novas propostas ao meio acadêmico, colocando novos (e velhos) desafios para a história e a historiografia no tempo presente.
\end{abstract}

Palavras-chave: Feministas Negras. Racismo. Interseccionalidade. Colonialidade.

\section{An epistemological (black) feminist turning point: concepts and debates}

\begin{abstract}
I intend to systematize in this article some debates that are perceived as central to black American feminisms, taking as subject of analysis American and Brazilian intellectual women, addressing their singularities and the complementarity of their speeches and discourses full of affections and examples of lives. Considering the feminist epistemic turn of the last decades, which departs from the concepts of intersectionality and (de)coloniality, I propose some parallels based on the location of black intellectual women, mapping the protagonism of marginalized subjects, who bring their experiences to academic theories and to political confrontation, inspired either by the voice of Sojourner Truth, in the USA, or by the "life-writing" (escrevivência) of Conceição Evaristo, in Brazil, together with the confidence in the orixás and the respect toward an ancestry of African matrix. Localized speeches that are told or written in first-person emerge from these narratives and they confront hegemonic epistemologies, bringing new proposals to academia and posing new and old challenges to history and historiography at present time.
\end{abstract}

Keywords: Black Feminists. Racism. Intersectionality. Coloniality. 
Nas últimas duas décadas, os debates, diálogos e trocas tomaram rumos distintos dentro do que historicamente se convencionou chamar "movimento feminista" - pelo menos até os anos 1990. De lá para cá, outras demandas sociais, culturais e fundamentalmente políticas foram sendo colocadas. O próprio conceito de feminismo começou a ruir diante das potências que se levantavam e se apropriavam também do espaço acadêmico, extrapolando o âmbito das lutas sociais, gerando um ativismo de característica epistêmica. Menciono diretamente o movimento de mulheres negras e o movimento LGBTQ+ (embora o intuito deste artigo seja trabalhar apenas com o primeiro). Ao mesmo tempo, emergem "feminismos", demarcando diferenças, ampliando territórios e se tornando uma espécie de guarda-chuva político capaz de abarcar movimentos e sujeitos distintos por meio de coalisões, da busca conjunta de uma coexistência pautada no respeito, na visibilidade e na luta por direitos amplos.

Pretendo percorrer um caminho teórico cruzado e complementar ao discorrer sobre a ascensão do conceito de interseccionalidade, que parte de um acirrado debate travado pelo feminismo negro acadêmico e que aos poucos vai sendo apropriado por outros sujeitos e movimentos, variando em sentido e intensidade de acordo com a localização, ampliando-se e recebendo críticas, a ponto de se tornar incontornável nos principais espaços de diálogo dentro e fora do Brasil, ainda que traga problemas de deslocamentos epistemológicos. Por fim, tratarei das trocas mútuas e de cruzamentos teóricos e práticos entre os conceitos de interseccionalidade e de decolonialidade, especificando os efeitos que alcançam, em conjunto, quando politicamente situados em diferentes escalas de localizações não centrais, sejam elas a latino-americana - incluindo a especificidade brasileira -, a nordestina e a sertaneja.

Para além desses conceitos, abordarei alguns dos questionamentos levantados pelos feminismos negros, tratados em sua pluralidade na contraposição entre as localizações estadunidense e brasileira. Assim, buscarei mapear e analisar de que modo algumas demandas do extracampo acadêmico, acionadas por movimentos sociais e pelos que denomino "sujeitos em situação 
de margem"1, traçam um percurso híbrido, que chega ao debate institucionalizado e desestabiliza os critérios que circundam objetos/sujeitos de pesquisas. E quando a própria filiação ao paradigma moderno-científico é desafiada.

Mais do que questões apenas conceituais, a irrupção e a apropriação desses conceitos por um campo intelectual reiteradamente tomado como periférico, e também pelo ativismo, potencializam essas noções, conectando teoria e realidade social, reflexões e ações políticas, entre elas as práticas de ensino, que possibilitam um encontro entre e com sujeitos outros da história, a junção entre pensamento decolonial e a potência do "ser periférico", que na visão apresentada por este artigo é considerado sujeito pleno e protagonista, distante da categoria de objeto a ser observado e analisado à luz de propostas conceituais, mesmo que elas coloquem em xeque as diversas perspectivas da colonialidade - do poder, do saber e do próprio ser.

\section{Um conceito para o ser periférico (do feminismo negro)}

Entendo que mesmo os conceitos mais longevos e incontornáveis são passíveis de críticas e questionamentos, já que emergem, permanecem e decaem no campo intelectual e nas práticas políticas, evidenciando desse modo aquilo que seus entusiastas muitas vezes pretendem ocultar - sua historicidade. Afinal, conceitos e teorias são acionados, depois rememorados, pela eficácia e a capacidade de sua relação com o chão do social, com grupos e sujeitos agentes de demandas e inquietações. Sendo assim, essas noções também podem ser datadas, capturadas pelo entendimento mais amplo de seu tempo em seu momento de ascensão. A emergência de um conceito já traz em si possibilidades de contestação e o horizonte de seus limites.

Pesquisadoras e pesquisadores do campo dos estudos feministas e de gênero têm se afirmado nos debates contemporâneos cada vez mais sobre o

\footnotetext{
1 "Margem" nos sentidos apontados por Kimberlé Crenshaw em 1991 no artigo Mapeando as margens: interseccionalidade, políticas de identidade e violência contra mulheres não-brancas (Crenshaw, 1991); e por bell hooks (1984) no livro Feminist Theory. from margin to center (Teoria feminista: da margem ao centro).
} 
conceito de interseccionalidade (PISCITELLI, 2008; HENNING, 2015), ou seja, na ideia de que a opressão social raramente anda sozinha; ela busca força e aliados em elementos específicos que demarcam diferenças. Se um homem é pobre e branco, sua exclusão dos espaços de poder se dará pela questão econômica. Se ele é pobre e preto, já podemos observar um cruzamento de opressões, cujo resultado multiplica cada um dos elementos colocados inicialmente. Se uma mulher é pobre, preta, periférica - podemos ainda acrescentar outras categorias, como lésbica (sexualidade), velha (geração), deficiente (capacitismo) -, o cruzamento desses marcadores de diferença atua diretamente sobre ela e seu lugar no mundo, já que ela é tudo isso ao mesmo tempo, inclusive mulher, estando situada na base de uma pirâmide social, cujo peso ela tem que suportar, enquanto o topo é ocupado por aqueles que não têm qualquer carga a assumir, como homens, brancos, heterossexuais e bem sucedidos - modelos inquestionáveis de uma tradição cultural herdada da modernidade.

Como relembrarei mais adiante por meio dos argumentos da teoria decolonial, a base dessa modernidade está fundada em seu contraponto inelutável, a colonialidade (QUIJANO, 2000). Para que exista o topo dessa pirâmide, é necessária a ratificação de sua base. Assim, nada será transformado e o conservadorismo estará a salvo de uma utópica justiça social.

No entanto, não precisamos ir tão longe para buscar o contexto histórico que possibilitou a emergência do conceito de interseccionalidade. Ele surge no horizonte de possibilidades de meados dos anos 1960, na esteira da história do movimento negro e dos feminismos negros, que já vinham dando sinais de sua potencialidade mesmo antes do fim da escravidão no continente americano. Um exemplo disso, que é retomado com frequência pelas feministas negras estadunidenses (também por algumas brasileiras)², é o pronunciamento da exescrava Sojourner Truth, em 1851, na Convenção dos Direitos das Mulheres que aconteceu em Akron, Ohio (EUA), pelo sufrágio universal - lembrando que as mulheres negras já estavam na luta sufragista desde a primeira metade do século

\footnotetext{
${ }^{2}$ Entre elas Angela Davis, bell hooks, Patricia Hill Collins, Carla Akotirene e Giovana Xavier. Sendo que as citações das brasileiras demonstram uma circularidade de saberes sobre os feminismos negros, que elas buscam no Brasil, mas também nas discussões colocadas por intelectuais de outros países.
} 
XIX (BRAH; PHOENIX, 2004). Sentindo-se provocada por um homem branco da plateia, que pretendia contrapor seus argumentos à reivindicação das mulheres, Truth proferiu um breve discurso, que ficou conhecido como E não sou eu uma mulher? e que seria reivindicado pelos feminismos negros mais de um século depois, remanescendo até a atualidade. Transcrevo e traduzo apenas um trecho:

Aquele homem ali diz que mulheres precisam ser ajudadas a entrar em carruagens e a passar por uma poça de lama e a ter o melhor lugar onde quer que esteja. Ninguém nunca me ajuda a entrar em carruagens, ou a passar por poças de lama, ou me dá qualquer melhor lugar! E não sou eu uma mulher? Olhem para mim! Olhem para o meu braço! Eu lavrei e plantei e ceifei nos celeiros e nenhum homem podia me ajudar! E não sou eu uma mulher? Eu podia trabalhar mais e comer mais do que um homem - quando pudesse ter comida - e suportar o chicote também! E não sou eu uma mulher? Eu pari treze crianças, e vi a maior parte delas ser vendida para a escravidão, e quando eu gritava minha dor de mãe, ninguém me ouvia, a não ser Jesus! E não sou eu uma mulher?

Sojourner Truth, $185 \beta$

Sojourner Truth foi buscada como ancestral inspiradora para o feminismo negro afro-americano pela ativista e acadêmica Angela Davis em 1981, no livro Mulher, raça e classe. Davis, assim como Audre Lorde, protagonizou com as mulheres negras as primeiras reivindicações de um movimento que ganharia visibilidade principalmente a partir dos anos 1970. Em paralelo aos movimentos sociais e de contracultura que abalaram o final da década de 1960 em algumas partes do mundo, o ativismo das mulheres negras marcava seu lugar. A base daquela pirâmide começava a apresentar suas primeiras fissuras de fato mais visíveis.

Nas palavras de Carla Akotirene (2018, p. 22), "[...] o projeto feminista negro, desde sua fundação, trabalha o marcador racial para superar estereótipos de

\footnotetext{
3 "That man over there says that women need to be helped into carriages, and lifted over ditches, and to have the best place everywhere. Nobody ever helps me into carriages, or over mudpuddles, or gives me any best place! And ain't I a woman? Look at me! Look at my arm! I have ploughed and planted, and gathered into barns, and no man could head me! And ain't I a woman? I could work as much and eat as much as a man - when I could get it - and bear the lash as well! And ain't I a woman? I have borne thirteen children, and seen most all sold off to slavery, and when I cried out with my mother's grief, none but Jesus heard me! And ain't I a woman?" Tradução minha. Cf.

https://www.feminist.com/resources/artspeech/genwom/sojour.htm.
} 
gênero, privilégios de classe e cis-heteronormatividades articuladas em nível global". Para esta autora, "é da mulher negra o coração do conceito de interseccionalidade" (Akotirene (2018, p. 24), sua ferramenta ancestral. Akotirene adverte sobre o mau uso dessa categoria de análise e a visão equivocada que surge quando ela é entendida apenas como a soma das opressões.

Em vez de somar identidades, analisa-se quais condições estruturais atravessam corpos, quais posicionalidades reorientam significados subjetivos desses corpos, por serem experiências modeladas por e durante a interação das estruturas, repetidas vezes colonialistas, estabilizadas pela matriz de opressão, sob a forma de identidade. (AKOTIRENE, 2018, p. 43-44).

Tanto Akotirene quanto outras e outros pesquisadores, entre eles Carlos Henning (2015), por motivos diversos e com perspectivas distintas, investigaram as origens do conceito de interseccionalidade em movimentos anteriores aos anos 1980/1990 nos Estados Unidos e na Europa. Uma influência importante foi a do manifesto de 1977 do Combahee River Collective, um coletivo de feministas negras lésbicas situado em Boston (nele estava Audre Lorde), que atuou entre 1973 e 1980. Para essas mulheres, a luta era articulada não apenas contra a opressão específica das mulheres, mas também contra outras formas de dominação com base em racismos, heterossexismos e a exploração por meio da classe social. Sexo, raça, classe, sexualidade estavam no centro das opressões entrelaçadas. Além disso, para o coletivo, considerado radical, era necessário "denunciar o racismo no movimento feminista de mulheres brancas." (HENNING, 2015, p. 102-103).

Embora observe a aglutinação de todas as mulheres feministas não brancas no termo feminismo negro, Avtar Brah (2006) destaca a relevância da criação da Organização de Mulheres Descendentes Africanas e Asiáticas em 1978 na Inglaterra. O debate estava em mais de um continente, sendo sistematicamente ignorado pelo feminismo das linhas centrais (mainstream), branco e preocupado com outras reivindicações, como o direito ao corpo, à igualdade política e de salários, entre questões e interesses que não se referiam necessariamente às mulheres não brancas. 
Vistas sob essa perspectiva, a mobilização das chamadas mulheres de cor e a própria conceitualização do que hoje entendemos como interseccionalidade acontecem inicialmente no extracampo acadêmico, elas estão inseridas nos movimentos sociais. O eixo central do conceito já estava colocado por essas mulheres e foi traduzido no livro de Davis (2016), publicado originalmente em 1981, como "mulher, raça e classe". No decorrer dos debates que viriam com os anos 1990, haveria uma adaptação desse eixo para "gênero, raça e classe". Também em 1981, bell hooks ${ }^{4}$ chamava para si a inspiração no feminismo negro sufragista de Sojourner Truth, provocando o debate interseccional a partir de seu Livro Ain't I a woman? Black women and feminism5 (HOOKS, 1991). bell hooks alimentaria essa discussão com outras obras suas, que serão abordadas na próxima seção. Essas autoras se tornaram referências incontornáveis no campo feminista e inspiradoras dos feminismos negros. Com elas teve início uma escala que se ampliaria cada vez mais, variando entre o local e o global, carregada e alimentada por especificidades próprias, que vão compondo os relevos diversos do debate.

Quando Kimberlé Crenshaw sistematizou, em 1989, o conceito de interseccionalidade, partindo do campo do direito, ela o fez tendo como sustentação todo o conteúdo herdado desse debate anterior. Sua abordagem se tornou a mais conhecida e discutida no Brasil e em outras partes do mundo, principalmente a partir dos anos 2000.

A interseccionalidade é uma conceituação do problema que busca capturar as consequências estruturais e dinâmicas da interação entre dois ou mais eixos da subordinação. Ela trata especificamente da forma pela qual o racismo, o patriarcalismo, a opressão de classe e outros sistemas discriminatórios criam desigualdades básicas que estruturam as posições relativas de mulheres, raças, etnias, classes e outras. Além disso, a interseccionalidade trata da forma como ações e políticas específicas geram opressões que fluem ao longo de tais eixos, constituindo aspectos dinâmicos ou ativos do desempoderamento. (Crenshaw, 2002, p. 177).

\footnotetext{
${ }^{4}$ Em minúsculas, como a autora prefere, para denunciar o seu lugar social como mulher de ascendência ao mesmo tempo negra e indígena. O nome "bell hooks" foi inspirado na sua bisavó materna, Bell Blair Hooks. (Hooks, 2019b, p. 38).

5 Não sou eu uma mulher? Mulheres negras e feminismo (tradução minha).
} 
Também Patricia Hill Collins $(2019)^{6}$ acabou sendo fundamental para a compreensão da articulação de categorias que ela trata no livro Pensamento feminista negro, que se tornou o seu trabalho mais conhecido.

Para Baukje Prins (2006, p. 279) apud Henning (2015, p. 111), as abordagens interseccionais de Crenshaw e Collins estão voltadas para questões estruturantes da identidade. Henning (2015, p. 109) atenta para o fato de que o conceito de interseccionalidade por vezes reforça alguns demarcadores de diferença que vão sendo repetidos ou alternados, tendo como principais a tríade raça, classe e gênero. Embora o autor não a cite, é de Jasbir Puar (2013) a referência a um "mantra” entoado com frequência sobre essas categorias, que a autora menciona no artigo "Prefiro ser um ciborgue a ser uma deusa": interseccionalidade, agenciamento e política afetiva”.

Mais do que o conceito, Puar critica suas apropriações. Para esta autora, se interseccionalidade - em um dos sentidos trabalhados por Kimberlé Crenshaw - permitiu repensar a política identitária partindo de dentro do feminismo negro, também vem sendo tomada como "noção primária para a teorização da diferença" em outros campos, como o da teoria queer (ou na queer of color critique), por exemplo. O motivo disso está na compreensão de que a diferença sexual e a de gênero se apresentam como constantes entre os componentes interseccionais, o que permite uma apropriação do conceito inclusive pelos sujeitos "mulheres brancas". Por outro lado, a noção de interseccionalidade é utilizada como método que qualifica a diferença específica das "mulheres de cor", como previa Crenshaw ao situar as mulheres negras como seu ponto de partida (PUAR, 2013, p. 347). Com a popularidade alcançada pelo termo, os feminismos fazem suas apropriações a partir da centralidade da categoria gênero, não mais da "raça". O problema, de acordo com Puar, não estaria na formulação de Crenshaw, mas na mudança da geopolítica da recepção, que acaba por reificar o conceito, levando-o para o campo do feminismo liberal branco. Trata-se, então, do que os feminismos negros chamariam de violência

\footnotetext{
${ }^{6}$ Opto por colocar entre colchetes o ano original da publicação, que tem relevância para o debate proposto.
} 
epistêmica, com a distorção dos objetivos de um conceito localizado que ganha centralidade. (2013, p. 350).

Para complicar ainda mais as excursões da teorização interseccionalista, tem-se que, nos Estados Unidos, a interseccionalidade adveio de um conjunto bastante específico de movimentos sociais, enquanto na Europa, onde o termo vem sendo atualmente adotado de forma ampla, o interesse pela interseccionalidade não emerge de movimentos sociais. (PUAR, 2013, p. 351-352).

Assim, para além de apropriações distintas, podemos pensá-las igualmente como localizadas, variando em termos de interesses de região para região. Também a serviço de políticas identitárias, que associam sujeitos, como pessoas trans e pessoas deficientes, por exemplo, ao conceito de interseccionalidade. Ou seja, o conceito emerge e ganha visibilidade porque havia demandas sociais que careciam dessa identificação conceitual.

Houria Bouteldja (2016) argumenta que, na atualidade, onde quer que ocorra um evento acadêmico, mais e mais pessoas evocam, no início de seus trabalhos, o mesmo "mantra" - raça, classe e gênero - como um pedido de permissão, para então seguir adiante; é como se apenas a menção e a reverência já isentassem autores e autoras de qualquer maior responsabilidade frente ao que pretendem apresentar. A reverência passa a ser automática, deixando de lado a autenticidade ou a originalidade do debate.

Pela crítica de Carla Akotirene, no Brasil o termo interseccionalidade virou um "modismo acadêmico", passando a ser utilizado em benefício pessoal, resultado de uma "apropriação intelectual indevida" por parte de "branquitudes brasileiras" (AKOTIRENE, 2018, p. 23-24). O apagamento epistêmico frequente das ferramentas conceituais dos feminismos negros requer uma prática reiterada do que a autora situa como a "descolonização do feminismo" - eu diria dos feminismos. A conceitualização acadêmica não está apartada do coletivo e dos movimentos sociais, segundo a perspectiva de Akotirene. "O conceito interseccionalidade está em disputa acadêmica, há saqueamento da riqueza conceitual e apropriação do território discursivo feminista negro quando trocamos a semântica feminismo negro para feminismo interseccional, retirando 
o paradigma afrocêntrico" (AKOTIRENE, 2018, p. 51). Sob a denominação feminismo interseccional (CRENSHAW, 1989, p. 52), faz-se uso do conceito, porém não de seu conteúdo, anterior à sistematização conceitual de Crenshaw em 1989.

Em termos de conteúdo e de vocabulário político, é certo que os feminismos negros têm muito mais a dizer do que girar em torno de um conceito, mesmo que de relevância central para seus objetivos e lutas. O ativismo do feminismo negro acadêmico nunca será somente acadêmico, pois finca suas raízes nos movimentos sociais e nas relações com a ancestralidade. É nas falas de feministas intelectuais negras, de dentro e de fora do Brasil, que busco linhas centrais e linhas de fuga - traçando paralelos e transgredindo a conceitualização europeizante de Deleuze e Guattari (2005) - para estabelecer uma amefricanização conceitual, mais ao estilo político irreverente de Lélia Gonzalez, que inspira e instrumentaliza o pensar feminista brasileiro e não-central. Mais do que linhas centrais ou de fuga, é possível pensar em linhas de confronto teórico, que partem das provocações colocadas na cena acadêmica pelos feminismos negros.

\section{A vez e as vozes dos feminismos negros}

Se, em 1851, a fala de Sojourner Truth, registrada a partir da oralidade, colocava em xeque a possibilidade, ou não, de ser uma mulher, diante dos padrões brancos e liberais da compreensão do que isso pudesse significar, muitas outras feministas negras seguiriam sua fala, tornando cada vez mais complexo o debate em torno da potencialidade intelectual e política das mulheres negras. Embora suas falas tragam elementos que as identifiquem individualmente em suas contribuições, é possível dizer que elas buscam uma complementaridade. Mais do que isso, essas intelectuais reivindicam a coletividade na luta por reconhecimento e respeito. Em movimento contrário ao academicismo produtivista, dito científico, que por vezes mina relações entre as mulheres em busca de um lugar ao sol no reconhecimento entre os pares

\footnotetext{
7 Publicado originalmente em 1995.
} 
intelectuais, o feminismo negro acadêmico valoriza as vozes que se colocam na confluência antirracista e entoa os mesmos cantos levados às ruas pelo ativismo social.

Para trazer algumas vozes no curto espaço deste artigo, busquei trechos de textos introdutórios de obras ou artigos de algumas feministas negras estadunidenses e brasileiras, no intuito de perceber de que forma articulam a demanda intelectual daquilo que se dispuseram a discutir.

Angela Davis, já mencionada, é uma das pioneiras mais citadas por intelectuais negras em todo o mundo, tendo ganhado visibilidade por sua militância desde os anos 1960, além dos textos publicados por ela. Em Mulher, raça e classe (DAVIS, 2016) a autora busca registrar histórias de luta dos negros e negras nos Estados Unidos, trazendo no capítulo intitulado "Educação e libertação, a perspectiva das mulheres negras" a informação de que o estudo e - conhecimento estavam entre os maiores anseios dessa população, principalmente das mulheres, pois sabiam que esse era o caminho para a longa transformação de sua condição social, historicamente imposta como inferior. A formação acadêmica fazia parte desse horizonte, sendo que o racismo era seu maior entrave (DAVIS, 2016, p. 77-79).8. Angela Davis, no clima acadêmico dos anos 1980, traça toda uma história do feminismo estadunidense de primeira onda, para nela destacar a participação das mulheres negras. Os tempos eram outros, e hoje podemos perceber algumas diferenças, como buscarei demonstrar logo abaixo. Essa autora e ativista estava preocupada não apenas com as mulheres negras, mas com toda a coletividade, incluindo homens, representados por companheiros, pais, filhos... todos sob a mira dos ataques racistas travados em seu país. O movimento antirracista teria que acontecer de forma ampla, já que as autoras aqui abordadas estiveram e estão imbricadas ao mesmo tempo nos dois movimentos - negro e feminista -, mesmo que isso implique em deslocamentos, em não serem contempladas em um ou em outro; daí a necessidade de articularem feminismos negros. Embora Davis tenha conseguido mapear mulheres brancas que participaram da luta antirracista, as mulheres

\footnotetext{
8 Publicado originalmente em 1981.
} 
negras tiveram que buscar caminhos próprios e construir estratégias para suas lutas.

Nos Estados Unidos, situamos igualmente os trabalhos de bell hooks, preocupada desde o início com as representações imagéticas e midiáticas das mulheres negras e com as possibilidades de uma autoidentificação por meio de imagens positivas. Para hooks, existe uma conexão entre a manutenção do que chama o "patriarcado supremacista branco" na sociedade estadunidense e as representações de raça e negritude que apoiam a opressão.

Teorizar a experiência de ser negra nos Estados Unidos é uma tarefa difícil. Socializadas no interior de sistemas educacionais supremacistas brancos e por uma mídia de massa racista, muitas pessoas negras são convencidas de que nossas vidas não são complexas e, portanto, não são dignas de reflexões e análises críticas sofisticadas. (HOOKS, 2019a, p. 32-33)

hooks, como outras feministas negras, entende que o trabalho acadêmico é um caminho a ser trilhado e mantido, possibilitando que a sua e outras vozes sejam ouvidas e que uma realidade compartilhada por elas seja debatida. "Já há algum tempo, o desafio crítico para as pessoas negras tem sido expandir a discussão sobre raça e representação para além dos debates envolvendo bons e maus conjuntos de imagens" (HOOKS, 2019a, p. 36). Segundo ela, é importante perceber o ponto de vista, a perspectiva política a partir da qual agimos, buscando transformar as imagens, subvertendo e procurando alternativas com "gestos de desobediência". A autora entende a descolonização como um processo político e uma luta de definição interna, que atua mesmo sobre lembranças do passado. Assim, bell hooks lança um olhar crítico sobre velhas narrativas, propondo outras leituras das subjetividades de pessoas negras, mas também das branquitudes (HOOKS, 2019a, p. 37-38). O que ela argumenta é que não basta ser negro ou negra, é preciso certa dose de progressismo e de pensamento descolonizado, sendo necessário cultivar o "autoamor" e amar a negritude como resistência política, pois, de acordo com hooks, há uma obsessão negra com a branquitude, que acaba expondo um entrave importante, o do ódio racial internalizado pelas pessoas negras. Para Patricia Hill Collins (2019a, p. 12),

\footnotetext{
${ }^{9}$ Publicado originalmente em 1990.
} 
compartilhar "pequenos momentos de amor umas com as outras na vida cotidiana" faz parte da resistência das mulheres negras. Acrescento que é nesse acolhimento amoroso que as linhas de confronto teórico começam a ser traçadas.

De acordo com bell hooks, ativistas feministas conscientes necessitam levar adiante "[...] uma teoria que fale sobre a importância de admitir que o reconhecimento e a aceitação positiva da diferença são um ponto de partida necessário enquanto trabalhamos para erradicar a supremacia branca" (HOOKS, 2019a, p. 51). Para essa autora, a solidariedade não depende da experiência compartilhada - portanto, não só das mulheres e feministas negras -, mas de escolhas políticas e de um entendimento ético que rejeitem o racismo e a dominação, que privilegiem o desenvolvimento da consciência crítica e de pontos de vista descolonizados. (HOOKS, 2019a, p. 52-53).

Em outro livro, intitulado Erguer a voz. pensar como feminista, pensar como negra, entre outras questões hooks (2019b) discute a importância dessas vozes para romper silêncios em torno das mulheres negras e ganhar alcance maior. "Encontrar nossa voz e usá-la, especialmente em atos de rebelião crítica e de resistência, afastando o medo, continua a ser uma das formas mais poderosas de mudar vidas por meio do pensamento e da prática feministas." (HOOKS, 2019b, p. 20-21). Ela entende que as relações entre o público e o privado necessitam ainda ser problematizadas também entre as feministas negras e argumenta que as questões pessoais que sempre estiveram na sua fala, com dificuldade começaram a chegar à escrita, "[...] pois muitas pessoas negras são criadas para acreditar que há muitas coisas sobre as quais não se deve falar, nem no privado nem em público." (HOOKS, 2019b, p. 25). Que dirá no meio acadêmico, onde tudo o que possa parecer não-científico causa arrepios?

bell hooks, nascida Gloria Jean, tomou o pseudônimo do nome de sua bisavó, uma mulher de língua afiada, que falava o que queria sem pedir permissão a ninguém, que não tinha medo de erguer a voz (HOOKS, 2019b, p. 38). Essa voz erguida é a mesma entoada pelos feminismos negros, em tom de luta e reivindicação. 
Fazer a transição do silêncio à fala é, para o oprimido, o colonizado, o explorado, e para aqueles que se levantam e lutam lado a lado, um gesto de desafio que cura, que possibilita uma vida nova e um novo crescimento. Esse ato de fala, de "erguer a voz", não é um mero gesto de palavras vazias: é uma expressão de nossa transição de objeto para sujeito - a voz liberta. (HOOKS, 2019b, p. 38-39).

bell hooks começou a escrever fazendo poesias, desde muito cedo. Esta parte de sua biografia se conecta a outra história, de uma mulher negra que escrevia poesia e que fazia questão de dizer que não era uma teórica do feminismo. Ainda assim, ela influenciou e se tornou referência para toda uma geração.

Falo agora sobre Audre Lorde, trazendo para o debate o capítulo "Age, race, class, and sex: women redefining difference", de seu livro Sister outsider. essays and speeches, publicado em 1984. Eu a cito:

Numa sociedade onde o bom é definido em termos de lucro, mais do que em termos de necessidade humana, sempre deve existir algum grupo que, através da opressão sistematizada, pode ser levado a se sentir como uma sobra, a ocupar o lugar do inferior desumanizado. Dentro desta sociedade, esse grupo é composto por pessoas negras e do Terceiro Mundo, da classe trabalhadora, pessoas mais velhas e mulheres ${ }^{10}$. (LORDE, 2007, sem paginação, tradução minha).

Audre Lorde afirma que sempre se sentiu parte de um grupo inferiorizado, desviante. Tal qual já alertava Frantz Fanon (2008)11, Lorde percebia que o recurso mais disponível para a sobrevivência era se apropriar dos códigos do opressor, familiarizar-se com seus costumes, seus modos e com sua linguagem. No entanto, para ela, é esperado das pessoas negras oprimidas que ensinem seus opressores, que as mulheres eduquem os homens, que lésbicas e gays eduquem o mundo heterossexual. Diferenças reais entre as pessoas, como raça, idade e sexo existem, mas não são elas que nos separam, segundo Lorde. O problema seria a recusa em reconhecer essas diferenças e as distorções que resultam na sua subnomeação diante dos comportamentos e das expectativas humanas.

\footnotetext{
10 "In a society where the good is defined in terms of profit rather than in terms of human need, there must always be some group of people who, through systematized oppression, can be made to feel surplus, to occupy the place of the dehumanized inferior.".

${ }^{11}$ Publicado originalmente em 1951.
} 
"Racismo, a crença na superioridade inerente de uma raça sobre todas as outras e, deste modo, o direito ao domínio. Sexismo, a crença na superioridade de um sexo sobre o outro e, deste modo, o direito ao domínio. Idosismo. Heterossexismo. Elitismo. Classismo”. (LORDE, 2007,sem paginação).

Para Lorde, na sociedade em que vivemos, as distorções são endêmicas, fazendo das diferenças barreiras intransponíveis. Sendo que a "norma mítica" seria o homem branco, magro, jovem, heterossexual, cristão e financeiramente estabelecido.

Entre as feministas, Audre Lorde entende que as diferenças de raça entre as mulheres trazem uma séria questão à mobilização conjunta, pois, enquanto as mulheres brancas ignorarem seus privilégios de branquitude e definirem "mulher" a partir apenas de sua própria experiência, as mulheres de cor se tornam as "outras", as outsiders, cujas experiências são alienígenas demais para serem compreendidas (LORDE, 2007, sem paginação). Ainda assim, Lorde vive o momento histórico de uma crença na "irmandade" (sisterhood) entre as mulheres. Assim como Davis e hooks, ela também reconhece a opressão racista sentida igualmente por mulheres e homens negros de uma mesma comunidade. A luta antirracista é de todos os grupos, assim como a luta feminista. Lorde vê a necessidade de uma coalisão para que aconteça a ação efetiva no combate ao racismo e ao racismo na especificidade das mulheres - e ela fala do ponto de vista de uma mulher negra, lésbica, periférica e que, com sua poesia e suas ideias, foi influência decisiva para outras feministas negras.

Em comum entre as autoras apresentadas até aqui, e mesmo as que virão a seguir, as vivências pessoais e os sentimentos, como mulheres negras, fazem parte de suas escritas, constituem suas teorias, o que entendo como suas linhas de confrontos teóricos.

É o caso também de Patricia Hill Collins, que no prefácio da primeira edição do livro Pensamento feminista negro conta uma história de seus tempos de criança, quando ela descobriu que a imagem linda que fazia de si própria aos quatro anos de idade diferia, em muito, daquela que o mundo externo (branco e racista) lançaria sobre ela e que tentaria convencê-la de sua veracidade. (COLLINS, 2019, p. 15). 
As autoras negras são unânimes ao colocarem em questão a autoestima das crianças, jovens e mulheres negras, sendo que muitas vezes as respostas acabam se dando por meio de um sentimento de raiva. Conseguir se expressar pode ser um caminho. "Ao longo da escrita, passei a ver meu trabalho como parte de um processo maior, como uma voz em um diálogo entre pessoas que foram silenciadas." (COLLINS, 2019, p. 19).

Patricia Hill Collins chama a atenção para como as mulheres negras preservam a humanidade diante da opressão. Com essa intelectual vem a proposta de uma linguagem mais efetiva e direta, que endereça outras mulheres. Passamos a usar o "eu", trazendo aquilo que é meu e que se refere a mim e a nós. Pautada na ética e na união, a autora propõe abordar o pensamento feminista negro evidenciando suas convergências, não as divergências. Importa a relação das mulheres umas com as outras, para fortalecer os afetos e o ativismo. Para Collins, o pensamento feminista negro nos Estados Unidos, com seus temas centrais e sua importância epistemológica, está inscrito em um contexto que desafia até mesmo o direito de existência dessas ideias. Suas "[...] principais formas de opressão são raça, classe, gênero, sexualidade, nação, idade e etnia", sendo que as três primeiras categorias caracterizam relações escravistas nos Estados Unidos, segundo ela. A eficácia dessas relações é representada pelo analfabetismo entre muitas mulheres negras jovens, confirmando sua exclusão de uma esfera social minimamente privilegiada. (COLLINS, 2019, p. 33).

Collins entende o pensamento feminista negro como teoria social crítica, produzida por um grupo historicamente oprimido. Na academia, as intelectuais negras seriam as outsiders within (forasteiras de dentro, complementando o argumento de Lorde). Sendo assim, o pensamento feminista negro diverge dos padrões da teoria acadêmica, buscando maneiras de escapar e de sobreviver à opressão. Artes e poemas, músicas e ensaios podem ser incorporados, todos agindo para a valorização das mulheres negras. "[...] caracterizando as experiências das estadunidenses negras marcadas por opressões interseccionais, a dialética entre opressão e ativismo também influenciou as ideias e as iniciativas das intelectuais negras" (COLLINS, 2019, p. 47). Para essa autora, há características que determinam o pensamento feminista negro. Elas passam pelo 
conteúdo, pelos referenciais interpretativos, pelas abordagens epistemológicas e pela importância da pesquisa e da escrita para o empoderamento das mulheres negras (COLLINS, 2019, p. 55-56), sendo que esse empoderamento só pode acontecer em um contexto transnacional de justiça social, de acordo com ela. (COLLINS, 2019, p. 59).

Collins denomina os produtos desse pensamento "saberes de resistência". Assim os entendo também, ao descer pela costa americana, chegando mais ao Sul, até o Brasil, lugar onde as feministas negras podem ter sido bastante influenciadas pela pauta internacional, mas de onde desenvolvem sua originalidade ao lidarem com os cruzamentos entre raça, gênero e classe como base de sua crítica e dos diversos debates que viriam a partir desse chão. E onde a colonialidade do saber (GROSFOGUEL, 2007), em suas vestes de rigor científico, apaga os rastros que historicamente a constituem.

Com a considerável entrada de pessoas negras nas universidades públicas brasileiras na última década e meia - resultado principal da lei de cotas - nós nos deparamos com um novo desafio para a historiografia brasileira contemporânea. As mulheres (também os homens) negras passam a constituir a real possibilidade da existência de um novo sujeito social, endereçado por seu hibridismo, borrando as noções de fronteira cultural e de barreira social. Por meio de coletivos e núcleos de estudo e pesquisa, essas mulheres se veem obrigadas não só a reorganizar sua situação de opressão, como a produzir instrumentos para seu entendimento, além do agenciamento no contexto acadêmico. Para pensar esta situação, uma renovação teórica que desse conta de seus múltiplos aspectos se fez necessária. Se as intelectuais negras estadunidenses se percebiam como silenciadas, o que podemos dizer das brasileiras, apartadas da chamada Englishness e dos circuitos de publicação que permitem uma inserção no diálogo mais amplo? Para além disso, quais os lugares designados a elas nas universidades ou mesmo em seus campos de pesquisa?

Giovana Xavier, por exemplo, relata que ao ser credenciada em um programa de pós-graduação, uma colega foi dar as boas-vindas a ela, dizendo que era muito bom que estivesse ali, por causa das demandas reprimidas de alunos/as que querem trabalhar com questões raciais (XAVIER, 2019, p. 90). Esta 
passagem mostra a complexidade dos debates, pois é a professora negra que acaba assumindo a responsabilidade, que ninguém se dispõe a tomar para si, sobre as discussões identitárias que chegam à universidade por meio de projetos de pesquisas. Esse lugar social acaba sendo incorporado, já que a luta antirracista é travada nas rachaduras e brechas do cotidiano. Xavier também assume a história do "eu", seguindo a proposta de Patricia Hill Collins, assumindo "[...] uma ciência 'na primeira pessoa', baseada em saberes científicos e comuns de mulheres negras." (XAVIER, 2019, p. 18).

Bebel Nepomuceno (2012) analisa o que chama "raízes da desigualdade" das condições das mulheres negras na sociedade brasileira, passando por questões centrais como o trabalho e a ausência histórica nas salas de aula, sendo que a educação foi a ferramenta e a sorte de raras mulheres negras que conseguiram atravessar as barreiras de classe e gênero impostas por uma cultura de características escravistas ainda não apagadas ou resolvidas. Espaço e voz são objetos de constante disputa e conquista.

Dentro das especificidades brasileiras, vemos ruir certos tabus acadêmicos de uma herança eurocêntrica, quando Carla Akotirene (2018), em trabalho recente, evoca os orixás e a ancestralidade ioruba como elementos que fazem parte da epistemologia feminista negra. "[...] beber da própria fonte epistêmica cruzada de mente-espírito" (AKOTIRENE, 2018, p. 20) é parte da proposta, aberta na graça de Exu, o senhor da encruzilhada. Trata-se aqui, segundo a autora, de uma "encruzilhada teórica" (AKOTIRENE, 2018, p. 22), essa de onde parte o pensamento feminista negro, intelectual, na "pegada" acadêmica/ativista brasileira. Para Akotirene, as feministas negras depositam sua confiança na "oferenda analítica" da interseccionalidade, preparada por suas intelectuais para poderem evidenciar seu apagamento e racismo epistêmicos. (AKOTIRENE, 2018, p. 23).

A interseccionalidade, pensada no Brasil, traz para o debate algumas questões específicas. Talvez seja fantasioso pensar que orixás e religiosidade de matriz africana possam aparecer na escrita de intelectuais afroestadunidenses, como as que trago para esta narrativa analítica. No Brasil, as linhas de confronto teórico são traçadas sob influências e possibilidades diversas. 
Se a filósofa Djamila Ribeiro (2019) ganhou visibilidade ao sistematizar a discussão dos feminismos negros brasileiros sobre "lugar de fala", ela nos leva à polêmica questão a respeito da qualidade dessa fala, de como utilizá-la quando assumimos esse lugar, já que visibilidade implica também em responsabilidade diante das expectativas da coletividade. Espera-se que o lugar de fala não se torne um argumento restritivo, já que a luta antirracista só busca agregar e até mesmo construir sensibilidades aliadas, que levem esse exercício para fora dos círculos feministas negros.

Localização é uma categoria central quando Ribeiro problematiza lugar de fala, inclusive em termos das metrópoles e das periferias acadêmicas - usando as palavras de Linda Alcoff (2016, p. 131) apud RIBEIRO (2019, p. 29). Djamila Ribeiro (2019, p. 31) relaciona lugar de fala à própria categoria “mulher negra”, pensada pelas feministas negras. "Uma mulher negra terá experiências distintas de uma mulher branca por conta de sua localização social, vai experienciar gênero de uma outra forma." (RIBEIRO, 2019, p. 60). No entanto, lugar de fala se refere mais a grupos sociais do que propriamente a indivíduos. (RIBEIRO, 2019, p. 62).

Com a proposta de interrogar esses lugares de fala, duas questões ficam bastante evidentes. Quem pode falar pelas mulheres negras? De onde essas mulheres negras estão falando? Para a primeira pergunta, vale lembrar que a própria constituição do pensamento feminista negro é coletiva, no entanto, pensar sobre quem representa essa coletividade pode abrir uma ampla reflexão. Não basta uma intelectual negra se destacar individualmente, se sua proposta fugir do significado coletivo do acolhimento, da valorização das outras, de fazer emergir o maior número de companheiras negras possível, para além dos embates externos antirracistas. Mas é importante situar que historicamente mulheres negras estiveram ausentes ou foram invisibilizadas na produção acadêmica e literária. Durante muito tempo, quando se falava em mulheres negras não era delas mesmas que partiam as falas. Se hoje esse espaço está sendo ocupado, às custas de muita luta, de reivindicações e de políticas públicas que vieram a atender a demandas sociais do movimento negro, estamos diante da vez e das vozes que chamam para si o direito e o espaço dessa fala. 
Entendo que a segunda questão se relaciona com a primeira, agregando a discussão sobre posicionamento dentro dos feminismos negros, tanto nas universidades quanto nos ativismos sociais que têm sua base consolidada fora delas. As acadêmicas são ativistas tanto quanto as outras e ocupam igualmente diversos âmbitos e arenas de debate. Na especificidade do Brasil, elas estão em grande número nas redes sociais que mobilizam trocas de saberes e discussões em torno desses feminismos.

\#pretadotora é a entrada nas redes sociais para o lado ativista da já citada Giovana Xavier. Conheci brevemente Giovana - intelectual, professora universitária, blogueira - entrando na fila de autógrafos de seu livro em um congresso nacional de história. Sem saber quem e o que estaria por trás da pequena mesa e das fotos que iam sendo tiradas, umas depois das outras exibindo livros autografados, eu me coloquei naquela fila de jovens mulheres negras, tentando saber com quem elas tanto se identificavam. Depois de quase meia hora, cheguei até Giovana e encontrei-a feliz com o sucesso do lançamento de Você pode substituir mulheres negras como objeto de estudo por mulheres negras contando sua própria história (Xavier, 2019). O título, a fila, meu interesse, minha própria história formaram o conjunto que levou à elaboração deste artigo.

Você pode substituir Mulheres Negras como objeto de estudo por Mulheres Negras contando sua própria história não é uma interdição às pessoas brancas. É sobre nós. É sobre a importância de localizar saberes e fazer ciência partindo dos lugares de fala de intelectuais negras. (XAVIER, 2019, p. 82).

Ao falar sobre posicionamentos desse "nós", Giovana Xavier dedica esse trabalho a "Xangô, homem dos búzios", e "Oyá, dona do céu cor de rosa pelo meu caminho". Assim como ela, Djamila Ribeiro inicia seu livro Lugar de fala agradecendo a Odé e quem cuida de seu Ori. Carla Akotirene também referencia os orixás das religiões de matriz africana. As referências a essa matriz e à ancestralidade, o respeito e a menção honrosa estão presentes como elementos que compõem essa versão brasileira da epistemologia feminista negra. Além disso, a referência a mulheres que, antes delas, abriram caminhos e ganharam reconhecimento é constante. Afinal, cada uma que sobe leva outras junto com ela. 
O conceito de escrevivência, da escritora e acadêmica Conceição Evaristo, aparece nos escritos de mais de uma das mulheres abordadas neste trabalho, já que buscam tratar epistemologicamente seus temas de interesse em conjunto com suas vivências singulares e coletivas como mulheres negras. Nessa compreensão, a escrita dessas mulheres está embebida daquilo que elas são.

Conhecimentos ligados à memória, oralidade, histórias, trajetórias familiares e demais narrativas das classes trabalhadoras, desqualificadas pelo mainstream. Menos do que resposta ao racismo institucional, essa nova epistemologia insere-se no desafio de colocar em prática projetos acadêmicos autônomos aos referenciais da ciência hegemônica. (XAVIER, 2019, p. 77-78).

[...] dar sustentabilidade ao trabalho de reposicionar as narrativas de mulheres negras das margens para o centro da produção acadêmica é trabalhar para reeducar as relações de gênero e raça no Brasil. (XAVIER, 2019, p. 92).

Sigo ainda com as palavras dessa historiadora voltada para o campo acadêmico da educação: "Assim, em meio a silêncios e conservadorismos, esse conjunto de textos [organizados em seu livro] coloca luz em novas formas de produção científica, localizadas nos saberes de mulheres negras”. (XAVIER, 2019, p. 77).

E quando eu utilizo, na escrita deste artigo, a mesma adjetivação “negra(s)" para a epistemologia, assim como para as mulheres, as intelectuais, e “negro(s)" para o movimento, para os feminismos e para o pensamento -, é com a consciência daquilo para o que Frantz Fanon já chamava a atenção no alvorecer dos anos 1950, em Pele negra, máscaras brancas, que para os homens brancos ou as mulheres brancas esse adjetivo não se torna necessário. O homem é um importante intelectual, não um importante "intelectual branco". A demarcação da diferença - "intelectual negro/a" - denuncia o deslocamento, a ocupação de um lugar inesperado. Por outro lado, como diversos termos de caráter pejorativo, o movimento "negro" se apropriou dessa adjetivação, fazendo dela elemento central nas estratégias políticas. Assim, o adjetivo se tornou uma afirmação identitária, sendo usado com consciência, objetivo político e orgulho.

Falar de consciência negra latino-americana - e assim vou cruzando também as teorias - é juntar a abordagem da interseccionalidade com a 
perspectiva decolonial, que caracteriza hoje a especificidade dos feminismos latino-americanos, incluindo neles questões sobre o Brasil e o Nordeste brasileiro - que destaco por serem solos dos meus interesses de pesquisa.

De acordo com Sueli Carneiro, "[...] a violação colonial perpetrada pelos senhores brancos contra as mulheres negras e indígenas e a miscigenação daí resultante está na origem de todas as construções de nossa identidade nacional, estruturando o decantado mito da democracia racial latino-americana" (CARNEIRO, 2011, sem paginação). Para ela, o racismo impacta e determina a hierarquia de gênero nas nossas sociedades. Esta especificidade faz com que seja necessário "enegrecer o feminismo", a partir da nossa localização.

Não sem propósito deixei para o final a referência à antropóloga e ativista brasileira Lélia Gonzalez, cujo pensamento pode ser tomado como ponto de intersecção entre os feminismos negros e os latino-americanos. O feminismo, como teoria e prática, na visão de Gonzalez, desempenhou um papel fundamental em nossas lutas e conquistas, na medida em que, ao apresentar novas perguntas, não somente estimulou a formação de grupos e redes, mas desenvolveu a busca de novas formas de ser mulher. Gonzalez sinaliza a ênfase dada à dimensão racial, relativa à percepção das mulheres no continente latinoamericano: "[...] no interior do movimento, as negras e as indígenas são as testemunhas vivas dessa exclusão". (GONZALEZ, 2011, p. 12)12.

A ativista e acadêmica percebe a importância dos movimentos sociais na formação dos feminismos negros acadêmicos, citando o exemplo dos Estados Unidos. Possivelmente, o pensamento feminista negro brasileiro ainda estava em fase inicial no final dos anos 1980, época em que a autora escreve o texto mencionado, buscando reverter a situação daquelas que não poderiam ser “sujeitos de seu próprio discurso” (GONZALEZ, 2011, p. 13). Para Gonzalez, o racismo era ocultado pelo feminismo latino-americano, que perdia força ao abstrair um dado central - o "caráter multirracial e pluricultural das sociedades dessa região”. Assim, “[...] pensar a divisão sexual do trabalho sem articulá-la com seu correspondente em nível racial é recair em um racionalismo universal

12 Publicado originalmente em 1988. 
abstrato, discurso masculinizado e branco". (GONZALEZ, 2011, p. 14). Falar da "opressão da mulher latino-americana" é falar de uma generalidade que oculta e tira de cena "a dura realidade vivida por milhões de mulheres que pagam um preço muito caro pelo fato de não serem brancas" (GONZALEZ, 2011, p. 14). Há perversidade no racismo latino-americano, visto por Lélia Gonzalez como sofisticado, já que mantém negros e indígenas na condição de segmentos subordinados, ao mesmo tempo em que estabelece uma ideologia de branqueamento, reforçando a universalização da cultura branca ocidental.

Em contraposição a esse sistema, os movimentos de mulheres que se articulam no continente envolvem aquelas que Gonzalez classifica como as amefricanas, ao lado das ameríndias - ambos os grupos sendo destinatários preferenciais da opressão.

São as filhas ou netas dessas mulheres amefricanas que passam a ocupar os espaços das universidades brasileiras a partir da década de 2000 e que potencialmente vêm a se tornar essa potência do feminismo negro acadêmico. No momento em que Lélia Gonzalez escreve seu texto, está sendo organizado o Primeiro Encontro Nacional de Mulheres Negras, em 1988 (GONZALEZ, 2011, p. 19). Ali foram plantadas muitas das sementes de um "feminismo afro-latinoamericano". Dito isso, proponho uma breve incursão pelo conceito de decolonialidade, pensando-o também em suas especificidades amefricanas e ameríndias.

\section{Descolonizar e interseccionar feminismos localizados}

A incontornável Gayatri Spivak (2010), em um texto que teve influência decisiva sobre os estudos feministas e pós-coloniais, lançou uma questão ainda não totalmente resolvida: Pode o subalterno falar? Este é o título do livro cuja tradução, talvez carente de maior elaboração, não levou em conta que, no argumento dessa autora indiana, "o subalterno" (não identificado por gênero no idioma inglês), em última instância é a mulher. Com base na perspectiva póscolonial, a análise de Spivak se encontra e é somada à de Kimberlé Crenshaw, cada qual em sua singularidade, ao oferecerem, ambas, bases teóricas para as diversas disciplinas que trabalham as interseccionalidades das mulheres do 
anteriormente chamado "terceiro mundo". As autoras citadas se apropriam da língua inglesa para expressar seu pensamento. O idioma, instrumentalizado, apresenta-se igualmente como um local ou uma possibilidade de fala, o pertencimento à já citada Englishness (GILROY, 2008; FANON, 2008). Afinal, na perspectiva latino-americana, quem pode ter sua obra traduzida, ganhando maior circulação e ampliando a recepção do conhecimento produzido?

Isto evidencia sentidos da própria História como área do conhecimento e suas narrativas com perspectivas teóricas e metodológicas construídas a partir desse desafio e dos (des)encontros da historiografia com os movimentos sociais, tendo como recorte temporal o período que se estende das últimas décadas do século XX até o presente, e como eixo condutor as apropriações pela historiografia de teorias originárias do que considero um extracampo da História composto, de um lado, por teorias produzidas em outros campos e disciplinas e, do outro, pelos conhecimentos e conceitos elaborados a partir da experiência de movimentos e sujeitos de resistência, com ênfase nos feminismos negros e no pensamento intelectual produzido e publicado por mulheres negras e as chamadas pejorativamente nos Estados Unidos de "mulheres de cor" (not Americans).

Como uma vertente dissidente dos estudos pós-coloniais ${ }^{13}$, a perspectiva teórica decolonial ${ }^{14}$ considera, além das permanentes estratégias de recolonização ou de neocolonialismo, a situação geopolítica latino-americana, que tem como consequência a sobreposição de opressões. Para além de uma luta de classes, os latino-americanos têm de enfrentar também os problemas da "colonialidade do poder", que se afirma sobre a racialização dos sujeitos, dos povos e dos espaços que habitam (QUIJANO, 2000). Não bastaram as independências, já que novas facetas da colonialidade vieram à tona, seja por

\footnotetext{
${ }^{13}$ Cujos marcos iniciais foram os trabalhos de Frantz Fanon: Pele negra, máscaras branca, 2008, publicado originalmente em 1951, sobre colonialismo; de Edward Said: Orientalismo, 2013, publicado originalmente em 1978; sobre o Ocidente e a predominância de sua visão sobre o Oriente; de Homi Bhabha: O local da cultura, 1998, publicado originalmente em 1990 sobre hibridismo cultural e; de Stuart Hall: A identidade cultural na pós-modernidade, 2000, sobre diáspora, representação, identidades e identificação.

14 Decolonial para distanciar-se da ideia do descolonial - conceito ligado ao movimento de descolonização durante e após o período das independências de países africanos no pósSegunda Guerra Mundial.
} 
relações econômicas ou pela sutileza da dominação cultural, que avança por meio das mídias, como o cinema, a propaganda, a internet e suas redes sociais virtuais (KELNNER, 2001). Está longe de ser vã a preocupação de bell hooks (2019a) com a representação das mulheres negras em imagens midiáticas.

O conceito de "colonialidade do poder" foi formulado por Aníbal Quijano em 1989 (atento para o fato de que esta noção é contemporânea ao conceito de interseccionalidade) e traria como novidade a leitura da raça e do racismo como princípios organizadores das hierarquias do que se denomina sistema-mundo, com foco nas localidades latino-americanas. Para Quijano (2000) ${ }^{15}$, o sentido moderno de raça não é conhecido antes da colonização da América. Ali fundase o binômio modernidade/colonialidade. Grosfoguel (2007) complementa esse pensamento com a ideia de "colonialidade do saber", demarcando uma geopolítica do conhecimento e dos sujeitos que produzem conhecimento científico. Como fica então a situação das mulheres nessa contextualização teórica?

É a argentina María Lugones (2008) quem aguça a crítica, apontando em Aníbal Quijano uma falha, ao não considerar o agravante gênero na perspectiva decolonial, ao menos não como fator determinante na relação binomial colonialidade/modernidade. No argumento de Lugones, o limite extremo das tensões na colonialidade do poder se encontra no que propõe como "colonialidade do gênero", agregando a interseccionalidade conceitualizada por Kimberlé Crenshaw e revitalizando a crítica de Gloria Anzaldúa. A colonialidade adquire seu caráter mais nefasto quando endereçada às mulheres, negras (amefricanas) ou indígenas (ameríndias), pobres, periféricas, geopoliticamente situadas em solo (latino-)americano. Eu acrescento: brasileiro, nordestino.

María Lugones (2008) e Glória Anzaldúa (2005) são autoras que dão maior complexidade à elaboração teórica sobre interseccionalidades nos territórios latino-americano e "chicano" (território latino dentro dos Estados Unidos) Anzaldúa teorizando sobre a mestiza e Lugones sobre colonialidade e gênero. ${ }^{16}$

\footnotetext{
15 Publicado originalmente em 1989.

${ }^{16}$ Outras autoras também se dedicam a pensar a América Latina sob essa perspectiva, entre elas as argentinas Karina Bidaseca (2016 e 2014) e María Luisa Femenías (2007), e a chilena Nelly Richard (2002).
} 
De todos os modos e acionando as teorias que podemos alcançar, trata-se de constatar e marcar posição nos diálogos sobre o "sujeito colonial". (BOUTELDJA, 2016), com ênfase para a situação das mulheres.

A perspectiva das histórias cruzadas $^{17}$ pode trazer uma contribuição importante para a abordagem investida aqui, já que as histórias, mas também a produção intelectual, dos diferentes territórios latino-americanos se cruzam desde o período colonial e as similaridades e distanciamentos entre elas podem ser analisados por meio dessa abordagem, que oferece elementos para uma reflexão que delimita espaços, mas expande horizontes temporais e teóricos.

A ampliação dessas teorias no campo da história se faz necessária ao aprofundamento de questionamentos sobre a inserção do Brasil na arena latinoamericana e estadunidense de debates (e já notamos algumas similaridades e diferenças geopolíticas dentro do próprio pensamento feminista negro), trazendo parâmetros e perspectivas críticas em relação a elaborações anteriores, também pensando possibilidades teóricas que deem conta de dialogar com movimentos sociais - negro e feminista - considerando a migração de parte de seus membros para o campo teórico-acadêmico.

A ocupação de espaços públicos já é um começo, mas está distante de dar conta da complexidade ${ }^{18}$ que contextualiza a emergência de protagonistas "outras", que ainda tateiam e lutam por seu lugar na história.

\section{Em busca de um lugar de fala para amefricanas sertanejas}

Percebo, com o estudo realizado e exposto neste artigo, a construção do que denomino uma "teoria em situação de margem", que ganha centralidade ao alcançar outras mulheres, como aquelas (nós) da fila de autógrafos,

\footnotetext{
17 Além de não trazer pretensões hierárquicas, o conceito de "histórias cruzadas" favorece uma análise que não descarta qualquer elemento específico de cada país, ou região (WERNER; ZIMMERMANN, 2010). Entendo que ele pode ser utilizado também em âmbito teórico.

18 Nas palavras de Sueli Carneiro (2011, sem paginação), “A utopia que hoje perseguimos consiste em buscar um atalho entre uma negritude redutora da dimensão humana e a universalidade ocidental hegemônica que anula a diversidade. Ser negro sem ser somente negro, ser mulher sem ser somente mulher, ser mulher negra sem ser somente mulher negra. Alcançar a igualdade de direitos é converter-se em um ser humano pleno e cheio de possibilidades e oportunidades para além de sua condição de raça e de gênero. Esse é o sentido final dessa luta."
} 
autoidentificadas com a intelectual, professora, doutora, blogueira que as (nos) representa.

São linhas de fuga cruzadas com linhas centrais, por vezes tomando delas esse lugar, ganhando visibilidade como linhas de confronto teórico, ecoando vozes que falam por si e tornam possível uma história dos feminismos negros composta "com" sujeitos/as, protagonistas e seus agenciamentos próprios.

Se a interseccionalidade já foi incorporada às propostas decoloniais, o caminho inverso ainda está por se concretizar. Entre as feministas negras citadas acima, destacam-se bell hooks, Carla Akotirene e Giovana Xavier como as que nominam e entendem como essencial uma "descolonização" do pensamento feminista, assim como do conhecimento acadêmico. Talvez falte ainda localizar esse pensamento feminista negro brasileiro como parte reconhecida dos feminismos latino-americanos na perspectiva decolonial, ou seja, amefricana lugar já ocupado por Lélia Gonzalez.

A circularidade de saberes, as apropriações e citações aparecem nos textos e nas falas, sejam elas acadêmicas ou informais, nas redes sociais. Patricia Collins, no prefácio para a edição brasileira de Pensamento feminista negro, argumenta que "temos muito a aprender umas com as outras no que diz respeito à maneira como os sistemas interseccionais de raça, classe, gênero e sexualidade se informam mutuamente em nossas respectivas configurações nacionais" (COLLINS, 2019, p. 12). Demonstra surpresa ao dizer que nunca imaginou que seu trabalho pudesse chegar tão longe. Esse "longe" se refere às leitoras, e leitores, do Sul global localizadas em território brasileiro. Mas há outras, nos interiores desse mesmo Sul, que habitam os sertões dessa periferia e que, aos poucos, procuram igualmente um lugar de visibilidade.

As jovens mulheres sertanejas que saem de suas cidades para estudar nas capitais ou nos centros maiores de seus estados, se tiverem sorte, conhecerão os argumentos da interseccionalidade e provavelmente se identificarão com eles; se tiverem um pouco mais, talvez se encontrem com questões sobre colonialidade e o pensamento crítico libertador oferecido por outras que vieram antes delas. É preciso teorizar para criar um diálogo com o chão do social, dentro dos espaços acadêmicos. É urgente estarmos abertas às trocas nas 
encruzilhadas de saberes para tentar agarrar ideias lançadas por outras mulheres, negras, indígenas, amefricanas, ameríndias, sertanejas. Seus saberes são de longa tradição, ligados às ervas e aos conhecimentos do espírito e do coração.

Mais do que disputas produtivistas, e as ansiedades cotidianas que acarretam $^{19}$, esse pode ser um caminho acolhedor, humanizado, que entrelace a intelectualidade às vivências das mulheres, a seus afetos. Que essa "teoria do acolhimento" faça muitos olhos brilharem e corações baterem mais forte na percepção de que nunca estaremos sós. O que aprendemos é para todas nós, o que trocamos ou ensinamos nos constitui como pessoas. O que escrevemos também é de todas e para todas nós ${ }^{20}$.

Nas salas de aula, milhares já estão ali, justamente a esperar por essas vozes. A força intelectual e o poder das ideias estão em discutir e lutar pelo que entendemos como certo e justo. Meu “eu” está presente neste texto, que finalizo esperando que toque e seja tocado por outras pessoas. Pensar e trabalhar por mulheres brasileiras em situação de margem, negras, indígenas, pobres, sertanejas é o possível para este momento. Eu, como não branca e acadêmica, falando a partir do Nordeste do Brasil, mapeio a história desse movimento intelectual, enquanto espero para saber quem mais irá se juntar a ele.

\footnotetext{
9 Giovana Xavier (2019, p. 77) entende que a academia e seus sentidos estão em constante disputa.

${ }^{20} \mathrm{E}$ aqui eu me refiro especialmente ao grupo de pesquisa "ProjetAH - História das mulheres, gênero, imagens, sertões" para que todas possam se reconhecer e se sentir contempladas com a discussão proposta.
} 


\section{Referências}

AKOTIRENE, Carla. Interseccionalidade. São Paulo: Sueli Carneiro/Pólen, 2018. (Coleção Feminismos plurais).

ANZALDÚA, Gloria. La conciencia de la mestiza: Rumo a uma nova consciência. Estudos Feministas, v.13, n.3, p. 704-719, 2005.

BOUTELDJA, Houria. Raça, classe e gênero: uma nova divindade de três cabeças. Caderno de Gênero e Diversidade, v.2, n.2, jul./dez. 2016.

BRAH, Avtar. Diferença, diversidade, diferenciação. Cadernos Pagu, Campinas, n. 26, p. 329-376, jan./jun. 2006.

BRAH, Avtar; PHOENIX, Ann. Ain't I a woman?: revisiting intersectionality. Journal of International Women's Studies, v. 5, n. 3, 2004.

CARNEIRO, Sueli. Enegrecer o feminismo: a situação da mulher negra na América Latina a partir de uma perspectiva de gênero. Geledés, 2011. Disponível em https://www.geledes.org.br/enegrecer-o-feminismo-situacao-da-mulhernegra-na-america-latina-partir-de-uma-perspectiva-de-genero/. Acesso em: 23/03/2020.

COLLINS, Patricia Hill. Pensamento feminista negro: conhecimento, consciência e a política do empoderamento. Trad. Jamille Pinheiro Dias. São Paulo: Boitempo, 2019.

CRENSHAW, Kimberle. Demarginalizing the intersection of race and sex: a black feminist critique of antidiscrimination doctrine, feminist theory and antiracist politics. The University of Chicago Legal Forum: feminism in the law - theory, practice and criticism, Chicago, p. 139-167, 1989. isṣp:

CRENSHAW, Kimberle. Mapping the margins: intersectionality, identity politics, and violence against women of color. Stanford Law Review, Califórnia, n.6, p.

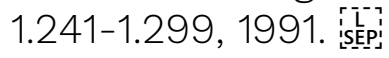

CRENSHAW, Kimberlé. Documento para o encontro de especialistas em aspectos da discriminação racial relativos ao gênero. Estudos Feministas, Florianópolis, v. 10, n. 1, p. 171-188, 2002.

DAVIS, Angela. Mulheres, raça e classe. São Paulo: Boitempo, 2016. 
DELEUZE, Gilles; GUATTARI, Félix. 1995. Mil platôs: capitalismo e esquizofrenia. Trad. Aurélio Guerra Neto e Celia Pinto Costa. São Paulo: Editora 34, 2005. v. 1.

FANON, Frantz. Pele negra, máscaras brancas. Salvador: EDUFBA, 2008.

GILROY, Paul. O Atlântico negro. São Paulo: 34, 2008.

GONZALEZ, Lélia. Por um feminismo afro-latino-americano. Caderno de Formação Política do Círculo Palmarino, Rio de Janeiro, n. 1, p. 12-20, 2011.

GROSFOGUEL, Ramón. Descolonizando los universalismos occidentales: el pluri-versalismo transmoderno decolonial desde Aimé Césaire hasta los zapatistas. In: CASTRO-GÓMEZ, Santiago; GROSFOGUEL, Ramón (coord.). El giro decolonial: reflexiones para uma diversidad epistémica más allá del capitalismo global. Bogotá: Siglo del Hombre, 2007.

HENNING, Carlos Eduardo. Interseccionalidade e pensamento feminista: as contribuições históricas e os debates contemporâneos acerca do entrelaçamento de marcadores sociais da diferença. Mediações, Londrina, v. 20, n.2, p. 97-128, jul./dez. 2015.

HOOKS, Bell. Olhares negros: raça e representação. São Paulo: Elefante, 2019a.

HOOKS, Bell. Erguer a voz: pensar como feminista, pensar como negra. São Paulo: Elefante, 2019b.

HOOKS, Bell. Ain't I a woman?: Black women and feminism. Boston: South End, 1981.

KELLNER, Douglas. A cultura da mídia - estudos culturais: identidade e política entre o moderno e o pós-moderno. Bauru: EDUSC, 2001.

LORDE, Audre. Sister outsider: essays and speeches, New York: Ten Speed Press, 2007.

LUGONES, María. Colonialidad y género. Tabula Rasa, Bogotá, n. 9, p. 73-101, jul./dic. 2008. 
NEPOMUCENO, Bebel. Protagonismo ignorado. In: BASSANEZI, Carla; PEDRO, Joana M. (orgs.). Nova história das mulheres. São Paulo: Contexto, 2012. p.382409.

PISCITELLI, Adriana. Interseccionalidades, categorias de articulação e experiências de migrantes brasileiras. Sociedade e Cultura, Goiania, v. 11, n.2, p. 263-274, jul./dez. 2008.

PUAR, Jasbir. Prefiro ser um ciborgue a ser uma deusa: Interseccionalidade, agenciamento e política afetiva. Meritum, Belo Horizonte, v. 8, n.2, p. 343-370, jul./dez. 2013.

QUIJANO, Aníbal. Colonialidad del poder y clasificación social. Journal of worldsystems research, v. 11, n. 2, p. 342-386, 2000.

RIBEIRO, Djamila. Lugar de fala. São Paulo: Sueli Carneiro: Pólen, 2019. (Coleção Feminismos plurais).

SPIVAK, Gayatri Chakravorty. Pode o subalterno falar? Belo Horizonte: Ed. UFMG, 2010.

WERNER, Michael; ZIMMERMANN, Bénédicte (dirs.). De la comparaison à l'histoire croisée. Paris: EHESS: Seuil, 2004.

XAVIER, Giovana. Você pode substituir mulheres negras como objeto de estudo por mulheres negras contando sua própria história. Rio de Janeiro: Malê, 2019. 